\title{
Cervical Non-Keratinizing Squamous Cell Carcinoma
}

National Cancer Institute

\section{Source}

National Cancer Institute. Cervical Non-Keratinizing Squamous Cell Carcinoma. NCI

Thesaurus. Code C40188.

A variant of cervical squamous cell carcinoma characterized by the presence of polygonal squamous cells. Intercellular bridges and cytoplasmic keratinization may be present, but keratin pearls are absent. 